\title{
A Proposal of an E-Learning Inter-Operable Platform Based on Semantic Web
}

\author{
Jimmy Rosales Huamani1, José Castillo Sequera², José Miguel Cañamero1, \\ Fabricio Puente Mansilla1, Gustavo Boza Quispe1 \\ ${ }^{1}$ National University of Engineering, Lima, Peru \\ ${ }^{2}$ Alcala University, Madrid, Spain \\ Email: jrosales@uni.edu.pe, jmiguel@uni.edu.pe, fpuentem@uni.pe, gbozaq@uni.pe, jluis.castillo@uah.es
}

Received 18 March 2015; accepted 16 May 2015; published 19 May 2015

Copyright (C) 2015 by authors and Scientific Research Publishing Inc.

This work is licensed under the Creative Commons Attribution International License (CC BY).

http://creativecommons.org/licenses/by/4.0/

(c) (i) Open Access

\begin{abstract}
Electronic learning, commonly called e-learning, has the goal of using technology to spread knowledge. Actually, the fast growing of Internet has allowed the creation of a variety of e-learning platforms. Thus there is the need for the regulation and interoperation of these platforms. Interoperability is a key factor in e-learning systems because it allows exchange and reuse of educational resources developed in different platforms. Problems may appear in their design and implementation because of the lack of interoperability among educative platforms contents. For that reason, it is important to use meaningful information to make possible the interoperability among different environments and to help in the management of proper contents. This is the area where Semantic Web may play a key role for reaching this goal. In this work, we propose the design of an e-learning platform prototype, that using semantic meaning, helps in the solution of interoperability problems.
\end{abstract}

\section{Keywords}

E-Learning Platform, Semantic Web, Ontology

\section{Introduction}

A decade ago the first Web based learning system appeared and since that, many universities around the world have added online resources as a complement to live teaching. The e-learning platforms have tried to evolve as Web does, adding new technologies and a great variety of tools. Despite of the great technological advance, people that use this resource still have trouble to find a system that fits their requirements. This is the reason why several developers are trying to implement several exact e-learning applications (García et al., 2008).

The e-learning evolution is parallel to the Web evolution and in building an e-learning system it is very 
important to hold student community trust inside a learning environment. Actually the real problems in e-learning systems are: semantic, efficient search of learning materials and interoperability.

According to (Stojanovic et al., 2001), Semantic Web contains a promising technology for building e-learning systems and helps in the solutions of the problems mentioned before. Today, there are several works with the use of Semantic Web technology for e-learning platforms. The motivation for this proposal is due to the existence of several e-learning platforms that contain the same educational content, but that information cannot be seen in another portal because they are different. Our proposal focuses on obtaining educative information from homogeneous external platforms, using Semantic Web technology. The information gathered from different platforms will be shown in a portal and it can be used later by a user through queries. The present work is divided as follows: in Section 2 we review related papers, in Section 3 real platform problems are presented, in Section 4 the prototype proposal is shown, and in Section 5 expected contributions are presented.

\section{Review of Literature}

The research was based in papers related to e-learning issues and Semantic Web. In this section, we review papers from 2009 to date because we think they are the more relevant to this subject.

In (Dutta et al., 2009), they stated that most of today e-learning systems provide static learning materials based on the philosophy of single size. The work identifies the fundamental e-learning systems problems and proposed possible solutions to the development of personalized learning system, deploying a modular side for ontology development. In (Daly, 2009), it is stated that the main objective of Semantic Web is to provide capacity to computers for understanding the existing web content in systems and servers through Internet. It is stated that if content interaction or content management is applied to e-learning environments, will cause an increase in a limitless way to its potential. Mainly, this can be done with the Semantic Web help. In (Pahl \& Holohan, 2009), they mention that the Semantic Web is based on the use of ontology, where a frame is shown for knowledge performance. The potential of this technology was used to develop content in those systems. Also and from (Shaikh et al., 2010), it is known that most of the searching drives are based on key words to answer a user request and these searching drives are too vulnerable for answering intelligent questions giving wrong and unreliable results. A Semantic Web layer model which offers a solution to this problem is proposed by supplying tools and technologies that allows computer to understand real web contents.

In (Shamsi \& Khan, 2012), they mention that e-learning is not efficient and learning duties are based in a just in time philosophy, and existing dynamic changes obligate for another design. Actually the Semantic Web includes efforts to build a new structure of this type in the Internet and the Semantic Web based model is presented for the e-learning system. In (Castellanos-Nieves et al., 2011) and because they stated that the use of Semantic Web technology in e-learning has become very important in the last years, they proposed to support evaluation of open questions in e-learning courses using Semantic Web technologies. This methodology combines ontology in its domain semantic notes and measurements of semantic similarity with a particular algorithm. In (Wu \& Wang, 2011), a prototype structure of intelligent service e-learning oriented is presented, where resources for learning are well defined by Semantic Web tools and information extraction is supported by web services.

In (Qwaider, 2012), it is stated, that the learning technology field has improved and is characterized by a great and growing number of suppliers of not homogeneous educational services. Effective usage of Semantic Web with its technologies is proposed to reach settings of advanced homogeneous learning. In addition, Semantic Web usage is presented as the main part of e-learning. From (Shah, 2012), it is known that Semantic Web can offer more flexibility in e-learning. It points out that the key factor is the structure of Semantic Web, which offers a powerful tool to satisfy e-learning requirements.

From (Rui \& Maode, 2012), it is known that traditional e-learning platforms have defects like inquires placed among crossed platforms. An e-learning system framework proposal is offered based in Semantic Web. In (Liu, 2012), it is stated that the integration of didactical resources in the school, is the key success in the implementation of e-learning in education. Even though, it is true that e-learning supplies a new learning path for the student, also it exists a phase of enormous defiance: build, organize, and integrate a variety of teaching resources in e-learning platforms. From (Khatri et al., 2012), it is known that Internet is allowing sharing big global information from data base storage and the amount of information grows exponentially. A structure based in an intelligent searching drive is presented that solves the searching problem efficiently.

Independently from (Sheeba et al., 2012), it is known that the representation of existing resources for 
e-learning systems does not have a unified standard and usually lacks of semantic information. It analyses semantic applied to learning contents at big scale for e-learning activities with a service oriented frame. In (Alier et al., 2012), they say that e-learning is in constant innovation, where new systems, contents, and software are in constant evolution. It is found that these systems present an interoperability problem among different environments. They tried to find a solution to this common problem supplying free specifications and the usage of open code. Then, in (Ghailani et al., 2012), an e-learning model that permits students to obtain pedagogical services is presented. They have as objective to answer the needs, at the same rate that their scientific curiosity and learning rate. A proposal of structure was presented.

In (Kara et al., 2012), an information extraction system based on ontology and recovering systems and their applications in football environment was presented. In general, this work comprises three subjects in semantic searching: usage facility, scalability and facility of recovery. The work also proposed a focus of semantic recovering based on keywords. The system was implemented using last generation technologies in Semantic Web and its performance was evaluated against traditional systems. In (Sanchez-Vera et al., 2012), they mentioned that feedback is an important element for learning environment evaluation, because it compounds a new learning opportunity not available in most e-learning systems. The article presents a focus to generate feedback to open questions in test evaluation. With the use of ontology and semantic notes, feedback is generated obtaining semantic similarity between notes associated with both questions and answers of students.

In (Arch-int \& Arch-int, 2013), they conclude with the existence of an increasing demand for sharing resources among existing learning systems, with the finality of support reuse, interchanging and adaptability. This research proposes the designation of ontology for interoperability of Resource Systems for Learning. In this work, reasoning rules are defined to classify learning objects related to the objective of improving deductive reasoning capacity of the system. As a consequence, ontology based in learning objects produce metadata and it is used by the drive of semantic consulting to facilitate users questions through learning resource systems. Also, in (Vasista \& AlSudairi, 2013), a structure based in semantic Web services is presented. In this work they used an independent platform with a structure oriented to services WSMX based (Web Service Execution Environment) for data integration. The WSMO (Web Services Modeling Ontology) was used. Finally, in (Murad, 2013) they concluded that despite the benefits of information structure, oriented to services. There are still a series of problems, and a way for a wide solution is to make interoperable services. It is proposed that using ontology and with semantic focus will solve the difficulties.

\section{Problems with E-Learning Platforms}

It is very important to build e-learning system, to keep confidence of students in a learning environment. There are certain benefits that traditional e-learning presents (Rosenberg, 2001), such us: Consistent and personalized information, the content is updated and reliable; updating is done at any time of the day, Web users receive the same material at the same time, scalability, building of communities, and cost reduction.

In addition to the above benefits, other factors that favor the implementation of e-learning systems are (Márquez, 2007):

- Economic factors: A better cost-effective relation for production and development, based on the reuse of technology components and related learning materials.

- High availability of digital resources: large companies need to distribute learning materials to geographically dispersed sites, so they are available anytime, anywhere.

- Social Penetration: the high penetration in society of new technologies in general and the Internet in particular favor the acceptance of new channels of information and communication.

However, there are several problems with today learning systems. In (Dutta et al., 2009) they quoted the following: lack of groups and environments of personalized learning, the whole learning material presentation ask continuous text, instead of only the proper information that a student is searching, the sequence of learning, re-usage, lack of inter operability, lack of semantic and quality assurance.

In addition to the problems mentioned before, there exist other factors like (Márquez, 2007):

- Dedicated staff: like students, teachers should have technical skills, knowledge and access hardware and software needed, to facilitate the design and development of TIC-based courses.

- Information Management: although possessing some technical skills and exceptional handling time, interfaces are required to reduce the logical and technical issues. 
- Equity: not all users have the same access to the Internet. The technology increases the differences between people that have technological facilities and those who have no such possibilities.

- Bandwidth: One of the biggest drawbacks is the bandwidth, which sometimes does not allow the diffusion of audio and synchronized video with good results.

\section{Proposal of Interoperable E-Learning Prototype and Semantic Consulting}

IEEE defines Interoperability as the ability of two or more systems to exchange data and to use the exchanged information. In e-learning system, inter-operability allows the exchange and reuse of resources (courses, documents, videos, tutorials, etc.), which have been developed in heterogeneous educative platforms, allowing the increase of the quality of available educative resources in the market. In addition, it guarantees that users of different hardware and software platforms can access the educative resources contained in heterogeneous sources (Aguirre et al., 2010).

The use of standards and technologies of Semantic Web is necessary for getting interoperability of educative resources among different systems. On this basis, the new proposal for an e-learning platform prototype will be postulated though the following stages:

1) Installing e-learning platform

Two free platforms will be installed, with the following steps: download the free software, installing the Platform, setting of the Platform, management of Platform, and finally creation of contents. Once installed the platforms, they will be completed with diverse educative contents of the same educative subject in different formats.

2) Building of Ontology

For an easy extraction of platforms content, ontology will be designed where knowledge about educative contents is placed to extract and compare later. Ontology will give us a vocabulary of classes and relationships, to describe the respective domain. For the constructing of the ontology, the ontological editor of Free Software called Protege, developed by Stanford University in collaboration with Manchester University, will be used. This software is very friendly and is based in a single model, similar to object oriented systems. The designed ontology will be in OWL (Ontology Web Language) (Yu, 2011) and for the modeling, the respective standards recommendations will be used. In particular the use of Methontology that is a methodology created by the Ontology Engineering Group of the Polytechnic University of Madrid (UPM), which comprises the following steps: Specification, conceptualization, knowledge acquiring, integration, planting, evaluation, and documentation (Fernández-López et al., 1997).

3) Interoperability making

For the e-learning platform information extraction, web services will be used, where success of interoperability is reached by adopting open protocols and standards (Rui \& Maode, 2012; Vasista \& AlSudairi, 2013; Wu \& Wang, 2011). For implementing and making the interaction among web services we will have to consider the usage of four sub groups:

(a) Transport service.

The responsible of message transport among applications on the web. It includes several protocols of application level.

(b) XML delivery.

It is the group in charge of codification of XML standard messages and it can be performed in any web nodes.

(c) Service description

Web service must have a public inter phase which is described by a format called WSDL (Web Services Description Languages).

(d) Service discovering

The UDDI (Universal Description Discovery and Integration) will be used, which is an independent frame of the platform used to describe services, businesses, and to integrate businesses services.

4) Ranking of obtained information.

Once acquired the information from e-learning platforms, Semantic Web technologies will be used to categorize information. This categorizing consists in getting similar terms of contents of a course from different e-learning platforms. An ontology will be designed containing the main important concepts for searching. In case that some ontology concepts are not found, a comparing algorithm will be used to obtain similar terms with ontology concepts. In this way, the requested information is obtained from a course content by the user. 
5) Prototype portal implementation

Once installed the platform, it comprises a diversity of information of different courses in general. Information can also be found to describe the courses taught by a specific teacher. In addition, registered students in a particular course can obtain semantic information from other platforms and interface is presented where content requested information will be shown.

Figure 1 shows the main ideas.

This conceptual scheme is based in three modules.

This module allows a user to make consult, asking the course he is taking and the subject he wants to study (the course can be found in the prototype platform and in external platforms). Once information is processed with the Knowledge Retrieving and Representation module, the requested results are shown to the user.

This module permits to make consulting, extraction of information from external e-learning platforms and in addition, the extracted information is send to a knowledge representation module, for processing. Web services will be used to get extracted information of the e-learning platforms.

In this module, knowledge in ontology previously designed is represented. This ontology will have the knowledge about educative contents to extract. In addition, it provides diverse concepts of a particular course in classes, sub classes and instances. Once obtaining the information from e-learning platforms, the Semantic Web technologies were used to classify information. To do so, information obtained by strings from external platforms are compared with the designed ontology that holds the concepts to search. To obtain similar terms among ontology and obtained information from platforms, a similarity algorithm is planned to use with an adaptation to this case (Wu \& Wang, 2011). This algorithm is useful for knowing the similarity level between two grouped collections in a tree shape. By this way, ranked information asked by user of a course from other platforms is obtained, and this obtained information is sent to the prototype portal for its presentation.

\section{Expected Contributions}

Actually there are works of interoperability with web services and also with the use of Semantic Web technologies in e-learning platforms (as shown in the state of the art) (Wu \& Wang, 2011). The contribution will be directed to use these technologies for improving e-learning teaching. This service will be used for extracting information from external e-learning platforms of any course allowing the user to complete his learning.

Once implemented the prototype portal, the following contributions are expected:

- An e-learning platform prototype that uses Semantic Web Tools to solve interoperability and semantic consulting. In addition, such prototype must manage e-learning contents.

- To release interoperability among homogeneous external platforms.

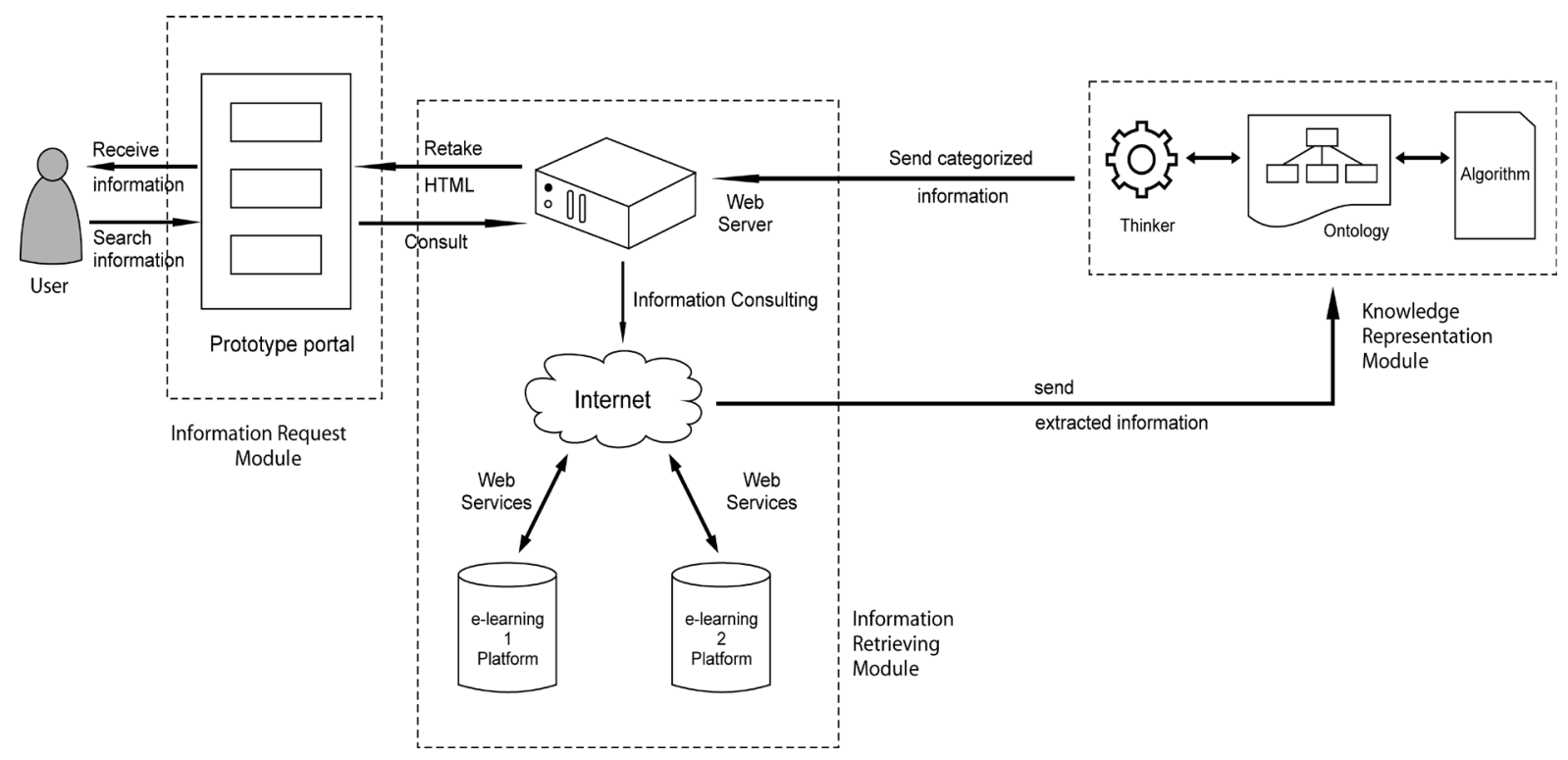


- To propose a conceptual architecture of the platform based on the developed prototype, because actually a similar architecture does not exist.

\section{References}

Aguirre, S., Quemada, J., \& Salvachua, J. (2010). Mediadores e interoperabilidad en elearning. http://reposital.cuaed.unam.mx:8080/jspui/handle/123456789/2267

Alier, M., Mayol, E., Casañ, M. J., Piguillem, J., Merriman, J. W., Conde, M. Á., Garca-Peñalvo, F. J., Tebben, W., \& Severance, C. (2012). Clustering Projects for eLearning Interoperability. Journal of Universal Computer Science, 18, 106-122.

Arch-int, N., \& Arch-int, S. (2013). Semantic Ontology Mapping for Interoperability of Learning Resource Systems Using a Rule-Based Reasoning Approach. Expert Systems with Applications, 40, 7428-7443. http://dx.doi.org/10.1016/j.eswa.2013.07.027

Castellanos-Nieves, D., Fernández-Breis, J. T., Valencia-Garca, R., Martnez-Béjar, R., \& Iniesta-Moreno, M. (2011). Semantic Web Technologies for Supporting Learning Assessment. Information Sciences, 181, 1517-1537.

http://dx.doi.org/10.1016/j.ins.2011.01.010

Daly, C. (2009). The Semantic Web and e-Learning. eLearn, 2009, Article No. 1. http://dx.doi.org/10.1145/1595384.1555528

Dutta, B., P Madalli, D., \& Prasad, A. (2009). Ontology Supported Personalized eLearning Repositories. http://eprints.biblio.unitn.it/1668/

Fernández-López, M., Gómez-Pérez, A., \& Juristo, N. (1997). Methontology: From Ontological Art towards Ontological Engineering. http://aaaipress.org/Papers/Symposia/Spring/1997/SS-97-06/SS97-06-005.pdf

García, V. M. Á., Ruiz, M. d. P. P., Pérez, J. R., \& Pérez, I. G. M. (2008). Presente y futuro del desarrollo de plataformas web de elearning en educación superior. Oviedo: Universidad de Oviedo.

Ghailani, M., El Bouhdidi, J., \& Fennan, A. (2012). Integration of Semantic Web in e-Learning Platform to Generate Appropriate Learning Paths. International Journal of Advanced Computer Science, 2, 464-469.

Kara, S., Alan, O., Sabuncu, O., Akpınar, S., Cicekli, N. K., \& Alpaslan, F. N. (2012). An Ontology-Based Retrieval System Using Semantic Indexing. Information Systems, 37, 294-305. http://dx.doi.org/10.1016/j.is.2011.09.004

Khatri, R., Dhindsa, K. S., \& Khatri, V. (2012). Investigation and Analysis of New Approach of Intelligent Semantic Web Search Engines. International Journal of Recent Technology and Engineering (IJRTE), 1, 2277-3878.

Liu, C. (2012). School-Based Teaching Resources Integration in the E-Learning Platform. IERI Procedia, 2, $247-252$. http://dx.doi.org/10.1016/j.ieri.2012.06.083

Márquez, V. (2007). Estado del arte del elearning. ideas para la definición de una plataforma universal. Ortega, Ramrez Juan Antonio DEA, Departamento de Lenguajes y Sistemas Informáticos, Sevilla-Spain: Universidad de Sevilla.

Murad, S. (2013). Using Semantic Services in Service-Oriented Information Systems. IEEE Potentials, 32, 36-46. http://dx.doi.org/10.1109/MPOT.2012.2187806

Pahl, C., \& Holohan, E. (2009). Applications of Semantic Web Technology to Support Learning Content Development. Interdisciplinary Journal of E-Learning and Learning Objects, 5, 1-25.

Qwaider, W. Q. (2012). Semantic Web Technologies Applied to E-Learning System. International Journal of Computer Applications, 47, 12-17.

Rosenberg, M. J. (2001). E-Learning: Strategies for Delivering Knowledge in the Digital. New York: McGraw-Hill.

Rui, L., \& Maode, D. (2012). A Research on E-Learning Resources Construction Based on Semantic Web. Physics Procedia, 25, 1715-1719.

Sanchez-Vera, M., Fernández-Breis, J. T., Castellanos-Nieves, D., Frutos-Morales, F., \& Prendes-Espinosa, M. P. (2012). Semantic Web Technologies for Generating Feedback in Online Assessment Environments. Knowledge-Based Systems, 33, 152-165. http://dx.doi.org/10.1016/j.knosys.2012.03.010

Shah, N. K. (2012). E-Learning and Semantic Web. International Journal of E-Education, E-Business, E-Management and E-Learning, 2, 113-116.

Shaikh, F., Siddiqui, U., Shahzadi, I., Jami, S., \& Shaikh, Z. (2010). Swise: Semantic Web Based Intelligent Search Engine. Proceedings of the 2010 International Conference on Information and Emerging Technologies (ICIET), Karachi, 14-16 June 2010, 1-5. http://dx.doi.org/10.1109/ICIET.2010.5625670

Shamsi, K. N., \& Khan, Z. I. (2012). Development of an E-Learning System Incorporating Semantic Web. http://arxiv.org/abs/1209.3117

Sheeba, T., Begum, S. H., \& Bernard, M. J. (2012). Semantic Web to E-Learning Content. International Journal, 2, 58-66. 
Stojanovic, L., Staab, S., \& Studer, R. (2001). E-Learning Based on the Semantic Web. Proceedings of the WebNet 2001World Conference on the WWW and Internet, Orlando, 23-27 October 2001, 23-27.

Vasista, T., \& AlSudairi, M. A. (2013). Service-Oriented Architecture (SOA) and Semantic Web Services for Web Portal Integration. Advances in Computing and Information Technology, 177, 253-261.

http://dx.doi.org/10.1007/978-3-642-31552-7 27

Wu, G., \& Wang, Y. (2011). Research on E-Learning System Prototype Based on Semantic Web Service Technology. Computing and Intelligent Systems, 233, 247-254. http://dx.doi.org/10.1007/978-3-642-24010-2_34

Yu, L. (2011). A Developers Guide to the Semantic Web. Berlin: Springer Science \& Business Media. http://dx.doi.org/10.1007/978-3-642-15970-1 